Article

\title{
Thermal Post-Treatments to Enhance the Water Stability of $\mathrm{NH}_{2}-\mathrm{MIL}-125$ (Ti)
}

\author{
Almudena Gómez-Avilés $\mathbb{D}$, Virginia Muelas-Ramos, Jorge Bedia * ${ }^{\mathbb{D}}$, Juan Jose Rodriguez and \\ Carolina Belver *(D)
}

Chemical Engineering Department, Universidad Autónoma de Madrid, Campus Cantoblanco, E-28049 Madrid, Spain; almudena.gomeza@uam.es (A.G.-A.); virginia.muelas@uam.es (V.M.-R.); juanjo.rodriguez@uam.es (J.J.R.)

* Correspondence: jorge.bedia@uam.es (J.B.); carolina.belver@uam.es (C.B.); Tel.: +34-91-497-29-11 (J.B.); $+34-91-497-84-73$ (C.B.)

Received: 20 April 2020; Accepted: 27 May 2020; Published: 29 May 2020

\begin{abstract}
NH}_{2}-\mathrm{MIL}-125$ (Ti) is a metal organic framework (MOF) based on Ti-oxo-clusters widely investigated in water-related applications. Such applications require MOFs with an excellent stability in the aqueous phase, but, despite this, the extent of MOFs' degradation in water is still not yet fully understood. In this study, we report a quantitative study of the water stability of $\mathrm{NH}_{2}-\mathrm{MIL}-125$ (Ti), analyzing the ligand release along the contact time in water. This study demonstrates that $\mathrm{NH}_{2}$-MIL-125(Ti) easily leached out over time while maintaining its structure. The effect of different thermal treatments applied to $\mathrm{NH}_{2}-\mathrm{MIL}-125$ (Ti) was investigated to enhance its water stability. The structural and textural properties of those modified MOFs were studied in detail and those maintaining the $\mathrm{NH}_{2}-\mathrm{MIL}-125$ (Ti) properties were exposed to aqueous medium. The analysis of the released ligand concentration in the filtrate can provide information on the water stability of this material.
\end{abstract}

Keywords: metal organic frameworks; $\mathrm{NH}_{2}-\mathrm{MIL}-125$ (Ti); water stability; purification

\section{Introduction}

Metal organic frameworks (MOFs) constitute a group of materials consisting of the repetitive assembling of organic linkers and cluster metal ions. The resulting crystalline structures have a large specific surface area and a well-defined porosity. Their physicochemical properties can be tailored by selecting the nature and combination of both components yielding numerous MOFs [1,2]. MOFs have gained growing importance in many applications, such as gas storage $[3,4]$, sensing $[5,6]$, membrane processes [7], drug delivery [8,9], and environmental remediation [10-13]. In this last field, MOFs have been investigated in water purification, especially as: (i) adsorbents for the removal of hazardous pollutants [14-16], (ii) catalysts for the degradation of contaminants by Advanced Oxidation Processes (AOPs), such as heterogeneous Fenton and photo-assisted treatments [17-19], and (iii) membrane materials for the separation of toxic substances from water streams [20]. The growing interest in these applications is leading researchers to develop MOFs with high stability in aqueous medium.

The literature describes examples of unstable MOFs that lose their structure and pore network when exposed to water, such as MOF-5, while others showed stability in water, even after months, or have not been fully tested in this respect [21,22]. The stability of MOFs can be related to an assembly-disassembly equilibrium where both the electronic and steric effects between the linker and the metal cluster play an important role. Several studies have shown that the instability under wet conditions depends on the metal-linker bond strength [23,24]. Using highly basic ligands or acid metals results in much stronger bonds and greater stability in water, as in the cases of ZIF-8 or Al-MIL-53 [25]. In addition, the linker structure, the nature of the metal and the coordination 
of the clusters also play an important role. Thus, hydrophobic linkers, inert metal cations and high-coordination clusters usually improve water stability. Moreover, high-charge metal ions lead to a stronger oxo-philic tendency that significantly strengthens the metal-linker bonds and improves the chemical stability of MOF [21]. Group-IV-metal- (Ti, Zr, Hf) based MOFs are examples of high-charge metal oxo-clusters, yielding abundant MOF structures with different coordination numbers and structural diversity [26-29]. Ti-based MOFs have received great attention because of their redox activity $\left(\mathrm{Ti}^{3+} / \mathrm{Ti}^{4+}\right.$ transition capacity), photochemical property and biocompatibility [30]. Those based on Ti-carboxylate complexes have high stability and their functional properties can be improved by organic functionalization, mainly by amine groups [31,32]. The degradation of MOFs exposed to water can occur by two different mechanisms, ligand displacement and hydrolysis [25]. The ligand displacement involves the exchange of a ligand by a water molecule, leading to the hydration of the metal and ligand lixiviation; while, upon hydrolysis, water dissociation occurs at the metal centers, the dissociated $\mathrm{OH}$ groups coordinate to the metal clusters and the metal-ligand bond is broken [33].

Nevertheless, predicting the water stability of MOFs remains qualitative and the literature is controversial, mainly due to the methodology used to assess the stability. The simplest process consists of exposing the MOF to water and comparing its properties prior and after a given contact time, mainly by weight loss, X-ray diffraction and $\mathrm{N}_{2}$ adsorption-desorption at $-196{ }^{\circ} \mathrm{C}$ [29]. Water adsorption-desorption isotherms are also useful since they provide information about the hydrophilic-hydrophobic character of MOFs [34]. Additionally, however, if the MOF is being considered for application in the aqueous phase, it should also be investigated whether the sample is partially dissolved [29,35]. Recently, Taheri et al. [36] performed a quantitative study of the ligand and $\mathrm{Zn}^{2+}$ released when ZIF-8 was immersed in water. They observed that the lixiviation of both species occurred during the first hour and after $24 \mathrm{~h}$ an equilibrium was achieved. No other studies deal with the analysis of the filtrate instead of the remaining solid in the literature. Lixiviation from the MOF must be considered for the sake of application in water remediation since the released metals and/or ligands can represent some hazards for the environment.

The literature contains examples concerning the post-modifications of MOFs to improve their water stability. Wen et al. [37] coated $\mathrm{NH}_{2}$-MIL-125(Ti) with a siloxane that increased its dye adsorption capacity while maintaining its crystal structure and morphology. Composites based on UiO-66- $\mathrm{NH}_{2}$ and a nitrile butadiene rubber sponge are more stable in water than the bare MOF because the sponge provides a hydrophobic character that prevents hydrolysis. These composites were shown to be efficient adsorbents for 2,4-dichlorophenoxyacetic acid removal from water and were easily recoverable thanks to its sponge conformation [38]. An interesting study has recently been reported, describing the improved water stability of ZIF- 8 by growing it along with $\mathrm{UiO}-66-\mathrm{NH}_{2}$, giving rise to a core-shell UiO-66-NH $\mathrm{N}_{2} @ \mathrm{ZIF}-8$ hybrid. This heterostructure showed excellent water stability, high adsorption capacity and selectivity for the separation of rare earths from water compared to other adsorbents [39]. Non-amine UiO-66 has been also incorporated in a composite membrane based on graphene oxide (GO) with a high water stability and highly efficient for dyes and antibiotics separation [40]. Although interesting, many of these modifications are not so easy to implement in technical applications.

Here, we focus the attention on $\mathrm{NH}_{2}-\mathrm{MIL}-125$ (Ti), a Ti-oxo-cluster MOF, due to its notable interest in water treatment by photocatalysis, a well-known AOP for the removal of different pollutants [1,41-43]. In a previous study, we demonstrated its high photocatalytic efficiency for the removal of some emerging pollutants and its stability during the reaction, comparing its structural, textural and morphologic properties before and after use [44]. However, in a preliminary test, additional organic matter was detected in the aqueous medium after reaction, thus suggesting that certain partial dissolution of the solid occurred. Thus, in this work, we initially studied the water stability of $\mathrm{NH}_{2}$-MIL-125(Ti) through a systematic analysis of the aqueous phase. Then, in order to improve its stability, $\mathrm{NH}_{2}$-MIL-125(Ti) was subjected to various thermal treatments. In particular, the study highlights that the stability of $\mathrm{NH}_{2}$-MIL-125(Ti) in water can be successfully improved, providing useful information for water-related applications. 


\section{Results and Discussion}

\subsection{Stability of the $\mathrm{NH}_{2}-\mathrm{MIL}-125$ (Ti)}

$\mathrm{NH}_{2}$-MIL-125(Ti) is an amine-functionalized isostructure of the MIL-125(Ti) formed by both octahedral and tetrahedral cages $[45,46]$. It is composed by titanium oxo-clusters and amino-terephtalate, both providing a high density of hydrophilic sites where water molecules can be adsorbed [47]. We had previously synthesized $\mathrm{NH}_{2}-\mathrm{MIL}-125(\mathrm{Ti})$, doped and successfully used as solar-light driven photocatalyst [44]. Although its structural stability under the reaction conditions was confirmed by X-ray diffraction, scanning electron microscopy and $\mathrm{N}_{2}$ adsorption-desorption at $-196{ }^{\circ} \mathrm{C}$, some ligand release was detected in the aqueous medium. To the best of our knowledge, there are no reports about the amount of linker leached when $\mathrm{NH}_{2}-\mathrm{MIL}-125$ (Ti) is put in contact with water. Thus, to determine the amount of released linker, $\mathrm{NH}_{2}-\mathrm{MIL}-125(\mathrm{Ti})$ was suspended in aqueous medium and the filtrates were analyzed, the leachate percentage being determined by:

$$
\text { Leachate }(\%)=100 \times \frac{C_{\text {linker }}}{\mathrm{C}_{\mathrm{NH}_{2}-\mathrm{MIL}-125(\mathrm{Ti})}} \cdot \frac{\mathrm{M}_{\mathrm{NH}_{2}-\mathrm{MIL}-125(\mathrm{Ti})}}{6 \times \mathrm{M}_{\text {linker }}}
$$

where $\mathrm{C}_{\text {linker }}$ is the linker concentration dissolved in the liquid phase $\left(\mathrm{mg} \cdot \mathrm{L}^{-1}\right), \mathrm{C}_{\mathrm{NH}_{2}-\mathrm{MIL}-125(\mathrm{Ti})}$ is the concentration of the MOF suspended in water, $\mathrm{M}_{\mathrm{NH}_{2}-\mathrm{MIL}-125 \text { (Ti) }}$ and $\mathrm{M}_{\text {linker }}$ are the molecular weight values of the MOF (1653.74 $\left.\mathrm{g} \cdot \mathrm{mol}^{-1}\right)$ and the linker (2-amino benzene dicarboxylate, $\mathrm{NH}_{2}-\mathrm{BDC}$, $179.12 \mathrm{~g} \cdot \mathrm{mol}^{-1}$ ), respectively. Figure 1a shows the evolution of dissolved linker and the corresponding leachate percentage upon contact time. $\mathrm{NH}_{2}$-MIL-125(Ti) undergoes relatively high linker leaching in water, which increases significantly over time to reach $40 \mathrm{mg} \cdot \mathrm{L}^{-1}$ after $24 \mathrm{~h}$, about $25 \%$ of the initial linker content of bare $\mathrm{NH}_{2}-\mathrm{MIL}-125$ (Ti). This leaching process occurs continuously over time, without reaching equilibrium. Similar behavior has recently been reported for ZIF-8, whose lixiviation started during the first hour and required one day to achieve equilibrium [36]. This leaching is detrimental regarding the potential water-related applications of $\mathrm{NH}_{2}$-MIL-125(Ti). For the sake of improving the stability of $\mathrm{NH}_{2}$-MIL-125(Ti) by reducing ligand leaching as much as possible, this MOF was subjected to different thermal treatments at different temperatures and holding times and under different atmospheres. The temperature was selected after studying the thermal behavior of this MOF by thermogravimetric analysis in air (Figure 1b). $\mathrm{NH}_{2}-\mathrm{MIL}-125$ (Ti) is thermally robust and suffers a strong weight loss of $54 \%$ within the 300 to $350{ }^{\circ} \mathrm{C}$ range, due to the oxidation of the organic linkers $[36,48]$. After increasing the temperature up to $500{ }^{\circ} \mathrm{C}$, a small weight loss $(9 \%)$ occurs, corresponding to the removal of the hydroxo-groups in the metal oxo-clusters, giving rise to $\mathrm{TiO}_{2}$, in a similar way to the analogous non-amine MIL-125(Ti) [46,49]. Based on this analysis, the $150-300{ }^{\circ} \mathrm{C}$ range was selected for the thermal treatment addressed to stabilize the $\mathrm{NH}_{2}-\mathrm{MIL}-125$ (Ti) without disturbing its structure and composition. 

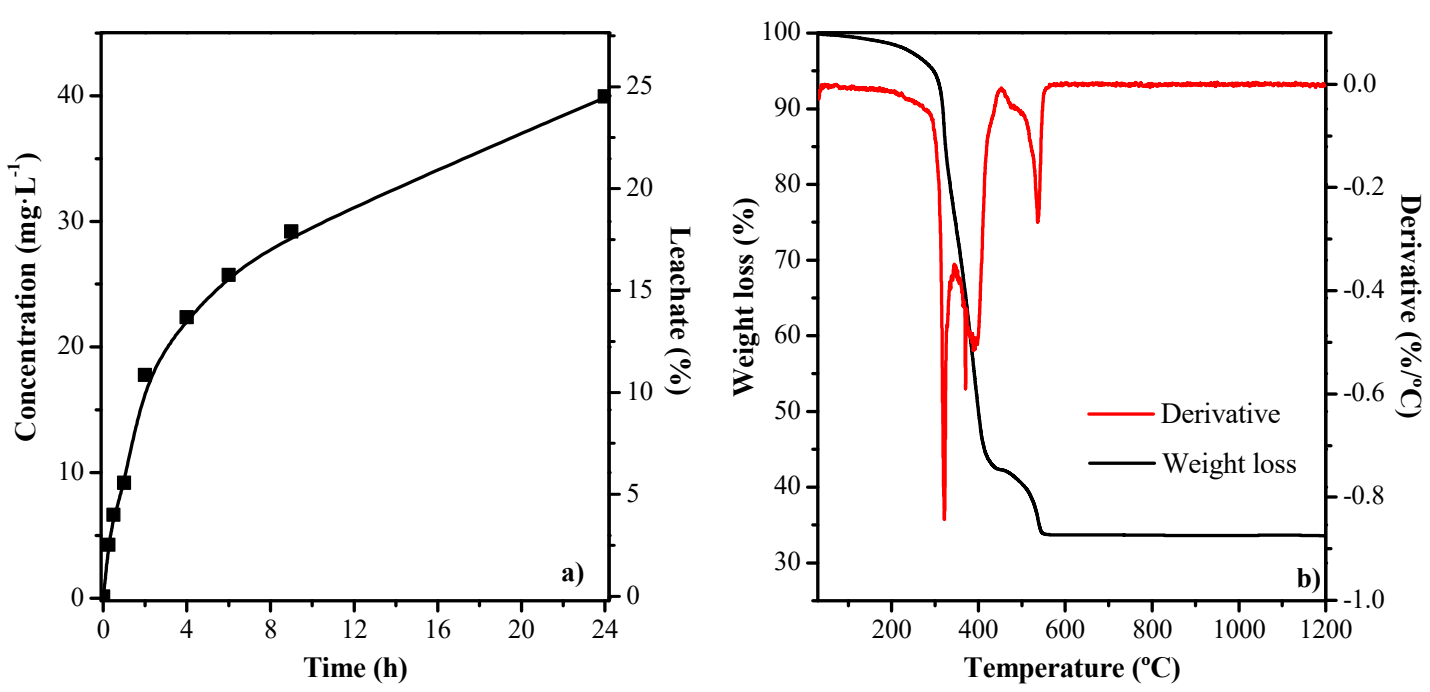

Figure 1. (a) Time course of linker concentration and leachate percentage in water from $\mathrm{NH}_{2}$ MIL-125(Ti) upon contact time; (b) thermogravimetric analysis in air of $\mathrm{NH}_{2}-\mathrm{MIL}-125$ (Ti) and its corresponding derivative.

\subsection{Vacuum Treatment}

During the synthesis of MOFs, excess ligand and solvent molecules can remain trapped in the pores of the framework, which can be detrimental for their future applications. In some cases, vacuum drying may be sufficient to purify the MOF, although it can lead to lower surface areas than expected due to the partial collapse of the structure [35]. $\mathrm{NH}_{2}-\mathrm{MIL}-125$ (Ti) was thus subjected to vacuum treatment in a temperature range of 100 to $300{ }^{\circ} \mathrm{C}$ for $16 \mathrm{~h}$ to remove the excess linker and solvent molecules. Figure 2 shows the X-ray diffraction (XRD) patterns of the modified solids compared with that of the bare $\mathrm{NH}_{2}$-MIL-125(Ti). In the notation, "V" refers to vacuum treatment, and the numbers represent the temperature $\left({ }^{\circ} \mathrm{C}\right)$ and time in hours of the vacuum treatment. As can be seen, this treatment does not modify the crystalline structure of the MOF until reaching $300{ }^{\circ} \mathrm{C}$. At this temperature, the $\mathrm{NH}_{2}-\mathrm{MIL}-125$ (Ti) structure collapses, and the resulting material does not describe any crystalline XRD profile, appearing as an amorphous material. Before that, a reduction in the peaks' intensity as the temperature increases is evidenced, indicating a gradual loss of crystallinity. Thus, the degree of crystallinity and the crystal size, as determined by the methodologies described in Section 3.2, are collected in Table 1. The greatest reduction on crystallinity was observed when reaching $250{ }^{\circ} \mathrm{C}$. However, since $\mathrm{NH}_{2}$-MIL-125(Ti) is an amine-functionalized isostructure of the MIL-125(Ti), both materials would show the same XRD profile, so it would be necessary to corroborate that the amine group in the ligand is maintained. The $\mathrm{NH}_{2}$ - $\mathrm{BDC}$ presence was confirmed by UV-vis spectroscopy (F1 in the supplementary information). Vacuum-treated samples showed two absorption bands, at 280 and $370 \mathrm{~nm}$, due to the absorption of Ti-oxo-clusters and $\mathrm{NH}_{2}-\mathrm{BDC}$ linker, respectively. Both bands characterize the $\mathrm{NH}_{2}$-MIL-125(Ti) and differ from the spectrum of MIL-125(Ti), which only has one band due to the absorption on Ti-oxo-clusters $[49,50]$. Scanning electron microscopy (SEM) and transmission electron microscopy (TEM) images of V-250-16 were taken and compared with those from the original sample (Figure 3). The MOF particles show a thin and disk-like shape with an average size close to $500 \mathrm{~nm}$, very similar to those of the $\mathrm{NH}_{2}$-MIL-125(Ti), which confirms that the vacuum treatment does not significantly modify the morphology of the MOF. 


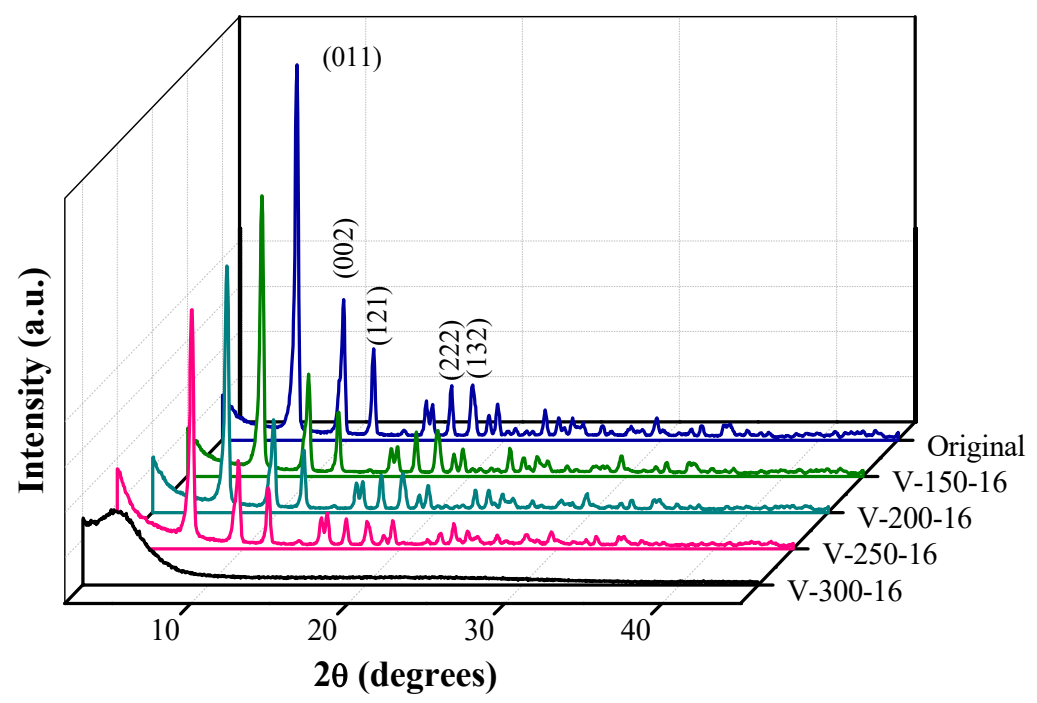

Figure 2. X-ray diffraction (XRD) patterns of the $\mathrm{NH}_{2}-\mathrm{MIL}-125$ (Ti) treated under vacuum at different temperatures for $16 \mathrm{~h}$. The original $\mathrm{NH}_{2}-\mathrm{MIL}-125$ (Ti) pattern is included as reference.

Table 1. Crystallinity percentages and crystal size values of $\mathrm{NH}_{2}-\mathrm{MIL}-125$ (Ti) before and after vacuum treatment at different temperatures for $16 \mathrm{~h}$.

\begin{tabular}{cccc}
\hline Sample & $\begin{array}{c}\text { Crystallinity } \\
\mathbf{( \% )}\end{array}$ & $\begin{array}{c}\text { Relative Crystallinity } \mathbf{1}^{\mathbf{1}} \\
\mathbf{( \% )}\end{array}$ & $\begin{array}{c}\text { Crystal Size } \\
(\mathbf{n m})\end{array}$ \\
\hline Original & 80.3 & 100.0 & 33.2 \\
V-150-16 & 75.0 & 93.4 & 30.9 \\
V-200-16 & 75.6 & 94.1 & 30.2 \\
V-250-16 & 63.6 & 79.2 & 21.2 \\
\hline
\end{tabular}

${ }^{1}$ Relative crystallinity to that of the original MOF.
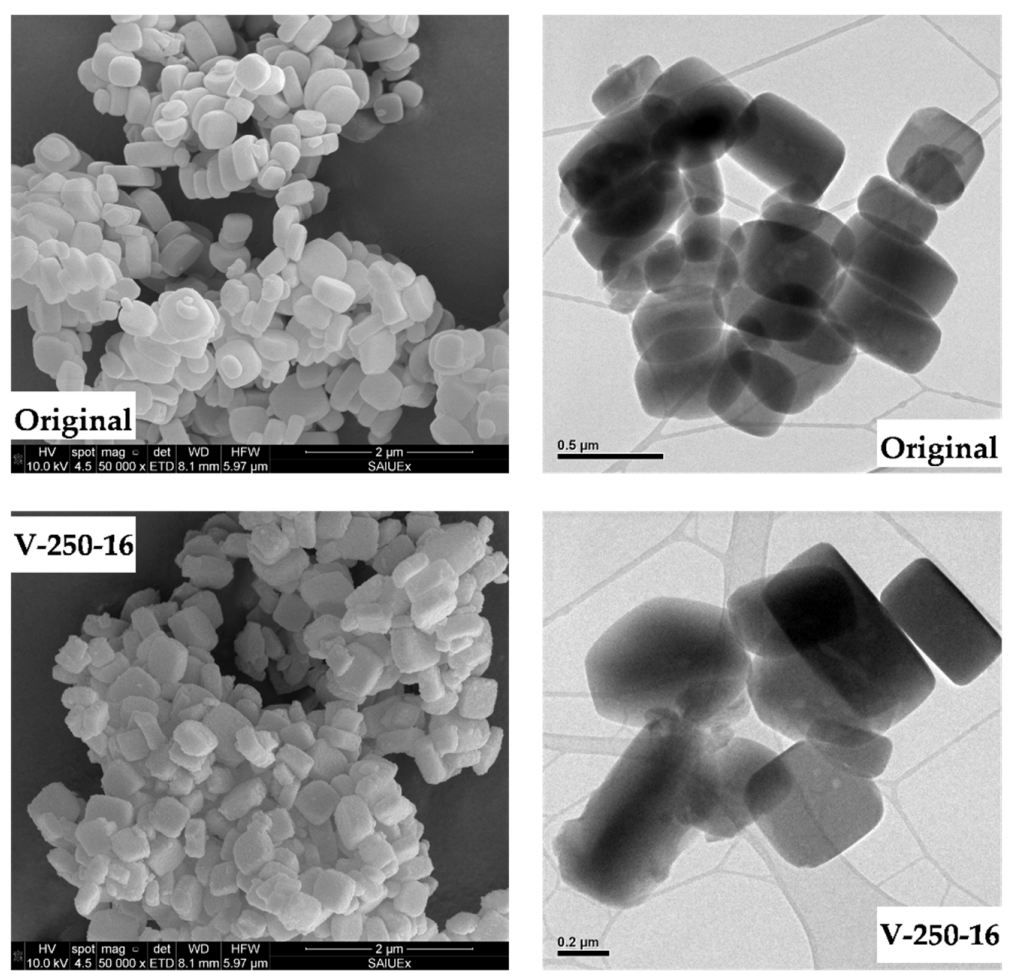

Figure 3. Scanning electron microscopy (SEM) and transmission electron microscopy (TEM) images of the original $\mathrm{NH}_{2}-\mathrm{MIL}-125$ (Ti) and V-250-16 sample. 
Figure 4 shows the $-196{ }^{\circ} \mathrm{C} \mathrm{N}_{2}$ adsorption-desorption isotherms of the $\mathrm{NH}_{2}$-MIL-125(Ti) subjected to the vacuum treatments and Table 2 summarizes the porous textural characteristics derived from those isotherms. Most of the solids treated under vacuum showed isotherms similar to that of the original $\mathrm{NH}_{2}$-MIL-125(Ti), indicative of predominantly microporous texture with some relative contribution of mesoporosity and fairly high surface area values [39,44,48]. Only the V-300-16 shows remarkable differences, with very low $\mathrm{N}_{2}$ adsorption and $\mathrm{S}_{\mathrm{BET}}$ due to the linker oxidation and structure collapse. It is worth noting that an increase in the temperature, below $300{ }^{\circ} \mathrm{C}$, is associated with some slight increase in the microporous surface, which can be related to the removal of adsorbed species, most probably excess linker and/or solvent molecules, not removed during the washing process that block the pore network [35]. According to these results, $250{ }^{\circ} \mathrm{C}$ appears to be the best temperature to carry out the vacuum-stabilization of the $\mathrm{NH}_{2}$-MIL-125(Ti), maintaining its structure and porosity.

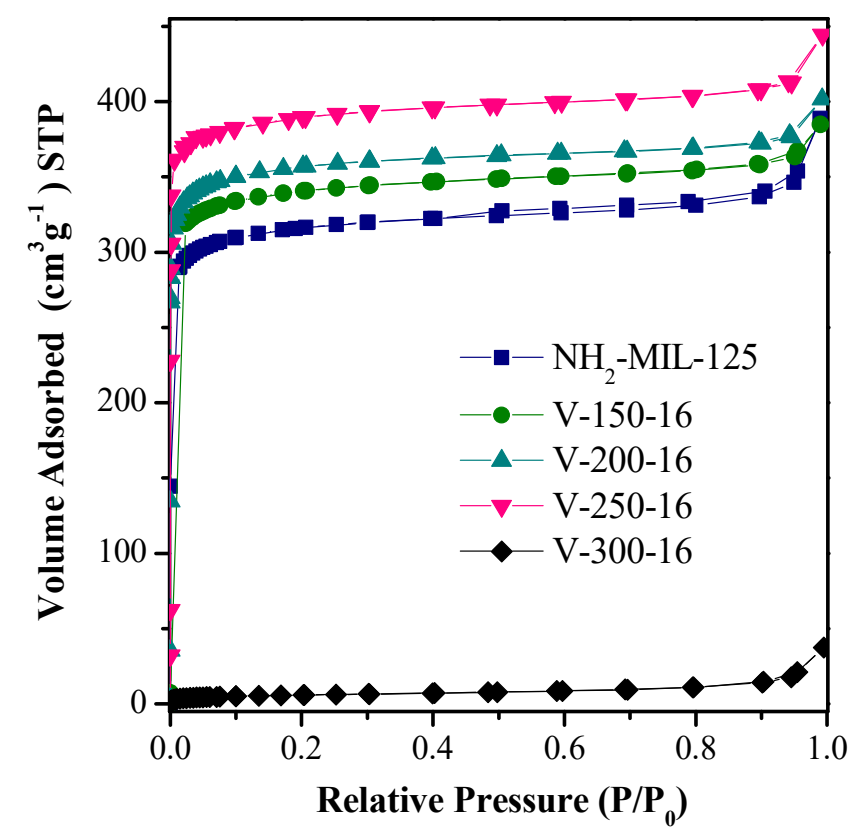

Figure 4. $\mathrm{N}_{2}$ adsorption-desorption isotherms at $-196{ }^{\circ} \mathrm{C}$ of the original $\mathrm{NH}_{2}-\mathrm{MIL}-125$ (Ti) and after treatment under vacuum at different temperatures for $16 \mathrm{~h}$.

Table 2. Porous texture characterization of the $\mathrm{NH}_{2}-\mathrm{MIL}-125$ (Ti) and after treatment under vacuum at different temperatures for $16 \mathrm{~h}$.

\begin{tabular}{|c|c|c|c|c|c|}
\hline Sample & $\begin{array}{c}\mathrm{S}_{\mathrm{BET}}{ }^{1} \\
\left(\mathrm{~m}^{2} \cdot \mathrm{g}^{-1}\right)\end{array}$ & $\begin{array}{c}\mathrm{S}_{\mathrm{MP}}{ }^{2} \\
\left(\mathrm{~m}^{2} \cdot \mathrm{g}^{-1}\right)\end{array}$ & $\begin{array}{c}\mathrm{S}_{\mathrm{EXT}}{ }^{3} \\
\left(\mathrm{~m}^{2} \cdot \mathrm{g}^{-1}\right)\end{array}$ & $\begin{array}{c}\mathrm{V}_{\mathrm{T}}{ }^{4} \\
\left(\mathrm{~cm}^{3} \cdot \mathrm{g}^{-1}\right)\end{array}$ & $\begin{array}{c}\mathrm{V}_{\mathrm{MP}}{ }^{5} \\
\left(\mathrm{~cm}^{3} \cdot \mathrm{g}^{-1}\right)\end{array}$ \\
\hline Original & 1025 & 940 & 85 & 0.60 & 0.45 \\
\hline V-150-16 & 1091 & 996 & 95 & 0.61 & 0.48 \\
\hline V-200-16 & 1103 & 1016 & 87 & 0.61 & 0.49 \\
\hline V-250-16 & 1154 & 1050 & 104 & 0.68 & 0.54 \\
\hline V-300-16 & 24 & 8 & 16 & 0.05 & 0.002 \\
\hline
\end{tabular}

Figure 5 depicts the evolution of the linker concentration analyzed in the liquid phase and the corresponding leaching percentage, upon contact time in water. The vacuum thermal treatment allows for significantly reducing the amount of linker leaching, that effect being more pronounced at a $200-250{ }^{\circ} \mathrm{C}$ treatment temperature. However, despite this reduction, there is still a considerable amount of linker in the liquid phase, corresponding to a 15\% leaching, and it is also noteworthy that the lixiviation does not reach an equilibrium, even after $24 \mathrm{~h}$. Therefore V-200-16 or V-250-16 samples cannot still be considered as stable materials regarding potential applications in the aqueous phase. 


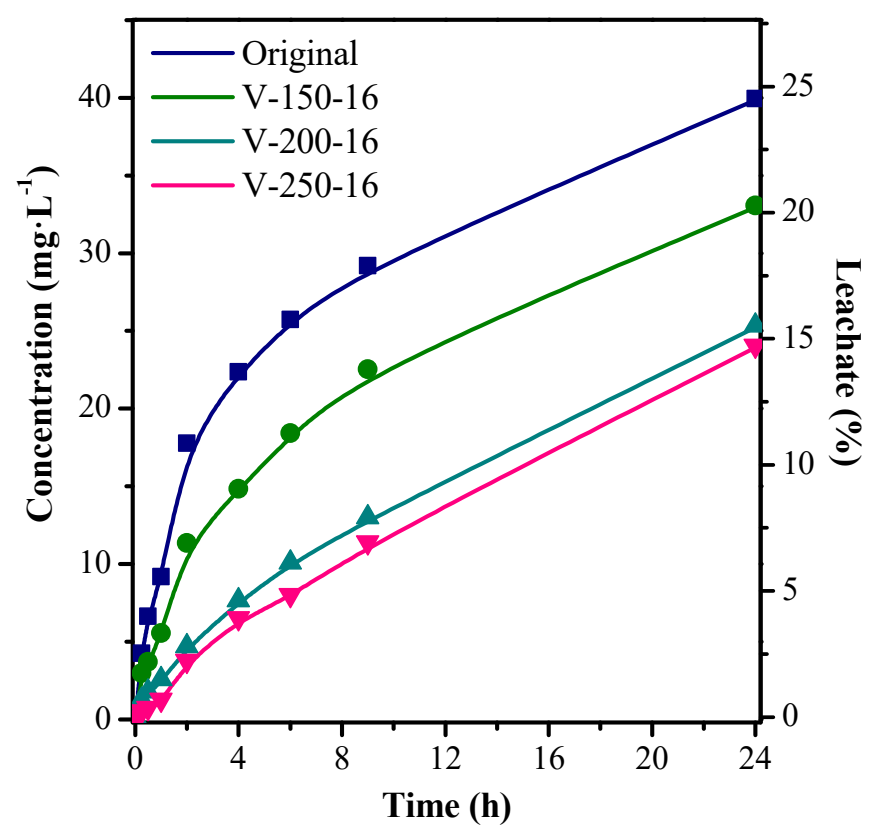

Figure 5. Linker leaching in water from $\mathrm{NH}_{2}-\mathrm{MIL}-125$ (Ti) before and after vacuum heat treated upon contact time.

\subsection{Thermal Treatment in Air Atmosphere}

Figure 6 depicts the XRD diffractograms of the $\mathrm{NH}_{2}$-MIL-125(Ti) subjected to calcination during $16 \mathrm{~h}$ at different temperatures in air-circulating muffle furnace. As previously observed in the vacuum treatment, the $\mathrm{NH}_{2}$-MIL-125(Ti) structure was maintained up to $250{ }^{\circ} \mathrm{C}$, while it collapses at $300{ }^{\circ} \mathrm{C}$, disappearing all the characteristic peaks of $\mathrm{NH}_{2}-\mathrm{MIL}-125$ (Ti). The degree of crystallinity and the crystal size of each sample are collected in Table 3. Increasing the temperature decreases the crystallinity of the samples, accompanied by a reduction in crystal size. These modifications can be related to the loss of solvent and excess linker molecules that are usually trapped in the MOF cages [35]. To learn more about the effect caused by air heating, additional treatments were conducted at $250{ }^{\circ} \mathrm{C}$, but extending the treatment time. Figure 7 compares the diffraction patterns of the samples heated for 16, 48 and $72 \mathrm{~h}$, where it can be seen that the characteristic peaks of the original structure are still remaining, but showing decreasing intensities as the calcination time increased, thus indicating a considerable gradual loss of crystallinity, reaching about $60 \%$ after $72 \mathrm{~h}$, which means a certain amorphization of the material.

Table 3. Crystallinity percentages and crystal size values of $\mathrm{NH}_{2}-\mathrm{MIL}-125$ (Ti) before and after heat treatment in air under different conditions. The values for M-250-48 after $24 \mathrm{~h}$ in contact with water are included.

\begin{tabular}{cccc}
\hline Sample & $\begin{array}{c}\text { Crystallinity } \\
\mathbf{( \% )}\end{array}$ & $\begin{array}{c}\text { Relative Crystallinity } \mathbf{1}^{\mathbf{1}} \\
\mathbf{( \% )}\end{array}$ & $\begin{array}{c}\text { Crystal Size } \\
\text { (nm) }\end{array}$ \\
\hline Original & 80.3 & 100.0 & 33.2 \\
M-150-16 & 79.2 & 98.5 & 33.5 \\
M-200-16 & 75.3 & 93.7 & 32.9 \\
M-250-16 & 63.7 & 79.2 & 31.1 \\
M-250-48 & 50.0 & 62.2 & 31.4 \\
M-250-72 & 34.1 & 42.4 & 32.9 \\
M-250-48-Exposed & 49.7 & 61.8 & 31.1 \\
\hline
\end{tabular}

${ }^{1}$ Relative crystallinity to that of the original MOF. 


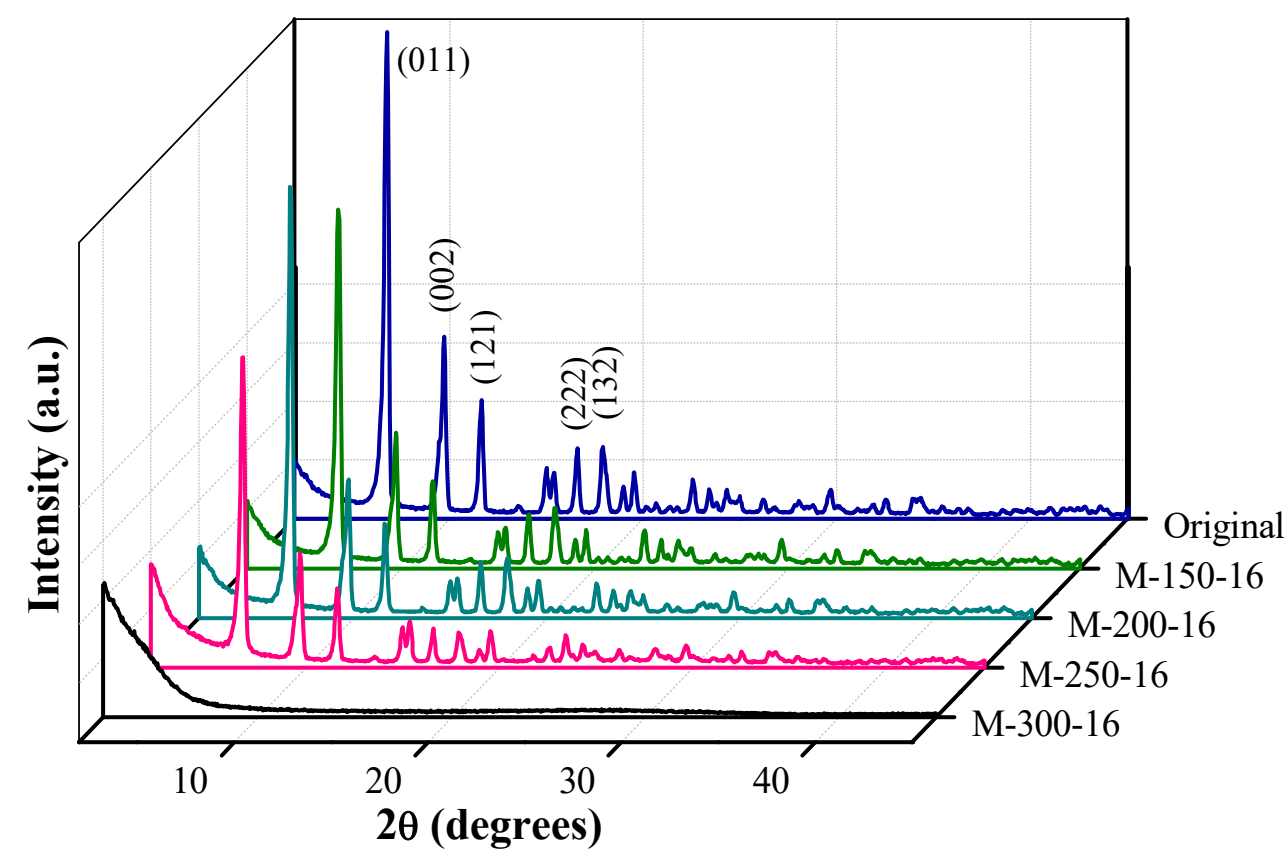

Figure 6. XRD diffraction patterns of $\mathrm{NH}_{2}-\mathrm{MIL}-125$ (Ti) heated in air at different temperatures for $16 \mathrm{~h}$. The original $\mathrm{NH}_{2}-\mathrm{MIL}-125$ (Ti) pattern is included as reference.

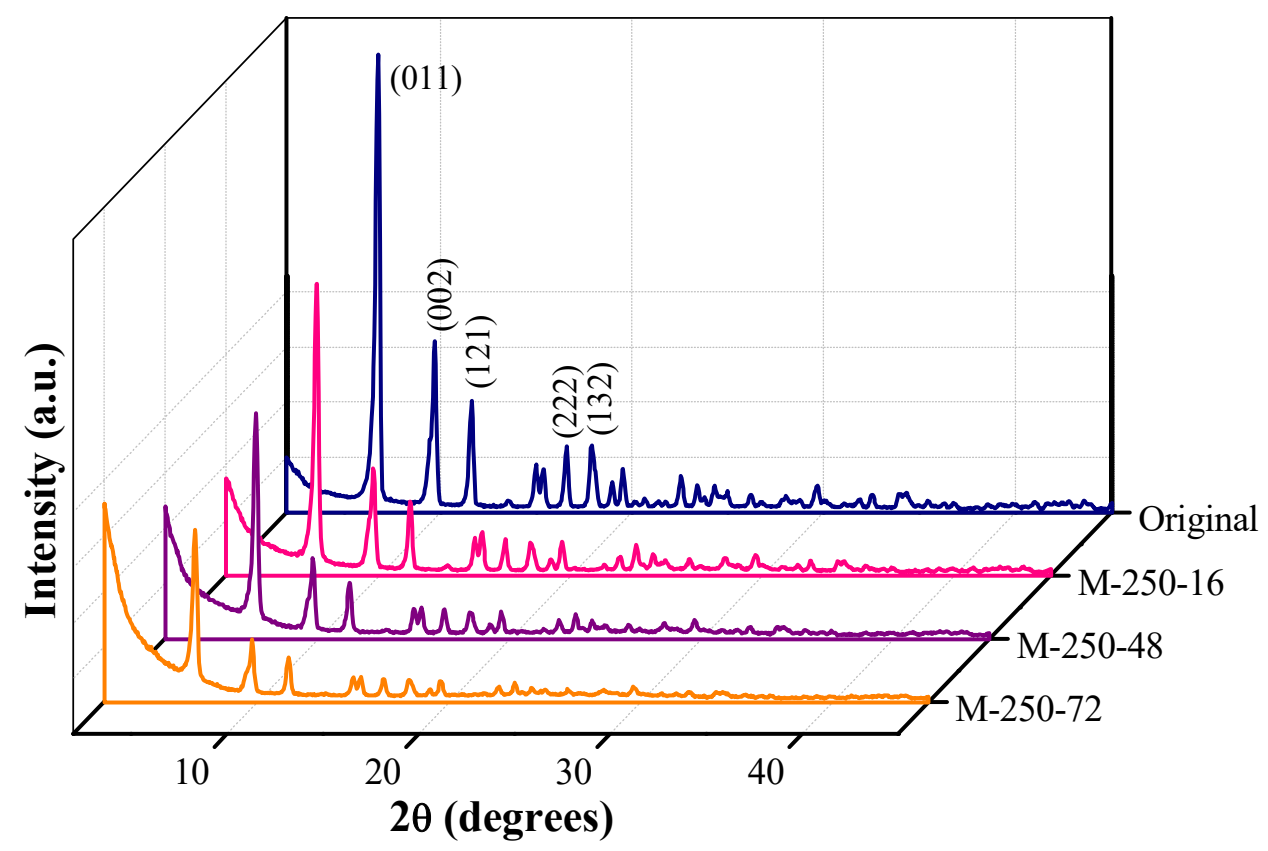

Figure 7. XRD diffraction patterns of $\mathrm{NH}_{2}$-MIL-125(Ti) heated in air at $250{ }^{\circ} \mathrm{C}$ for 16,48 and $72 \mathrm{~h}$. The original $\mathrm{NH}_{2}-\mathrm{MIL}-125(\mathrm{Ti})$ pattern is included as reference.

Once again, the presence of $\mathrm{NH}_{2}$-BDC in all heat-treated samples was confirmed by UV-vis spectroscopy (Figure S2 in the supplementary information). The UV-vis spectra showed the two absorption bands characteristic of the $\mathrm{NH}_{2}$-MIL-125(Ti), unlike the single band that characterizes the MIL-125(Ti) [49,51,52]. Figure 8 collects SEM and TEM images of some calcined samples that can be compared with those of the original $\mathrm{NH}_{2}-\mathrm{MIL}-125$ (Ti) shown in Figure 3. As can be clearly observed, the morphology of M-300-16 is very different. The well-defined disk particles of the $\mathrm{NH}_{2}-\mathrm{MIL}-125$ (Ti) disappeared and became an amorphous morphology, corroborating the structural collapse described 
above. However, the morphology and disk-shape of the original MOF remained after thermal treatment at $250{ }^{\circ} \mathrm{C}$ for $48 \mathrm{~h}$, as well as the particle size $(\approx 500 \mathrm{~nm})$.
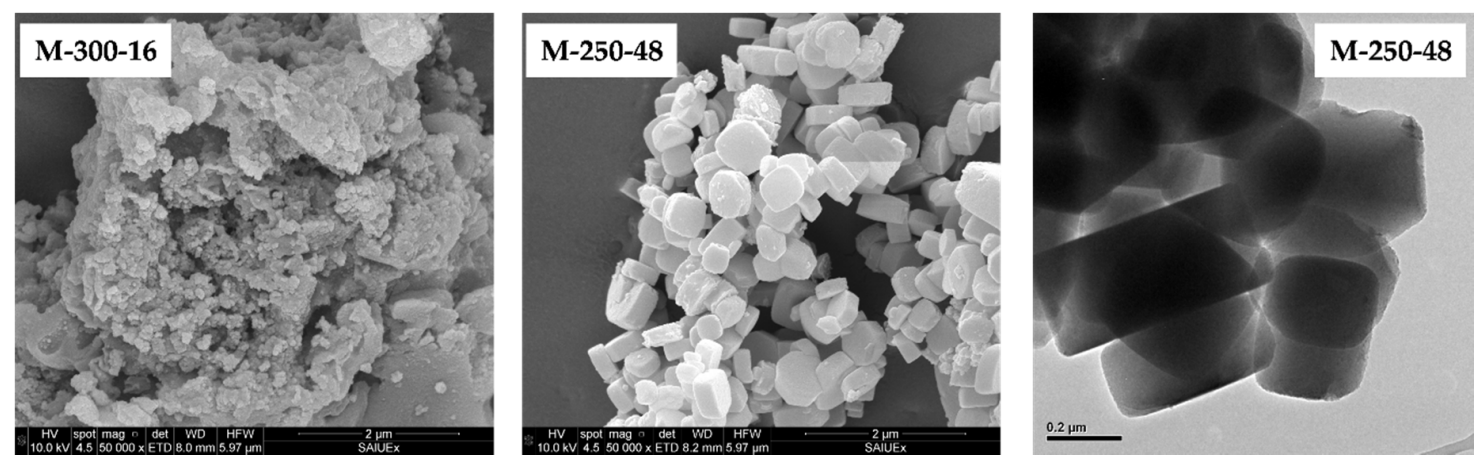

Figure 8. SEM image of M-300-16. SEM and TEM images of M-250-48.

Figure 9a depicts the $-196^{\circ} \mathrm{C} \mathrm{N}_{2}$ adsorption-desorption isotherms of $\mathrm{NH}_{2}$-MIL-125(Ti) subjected to thermal treatments in air and the derived porous textural characteristics are summarized in Table 4. As in the case of heat treatment under vacuum, these samples showed an isotherm typical of microporous solids $[39,44,48]$. Again, the calcination in air at $300^{\circ} \mathrm{C}$ caused the loss of structure and the collapse of the pore network, resulting in a $\mathrm{N}_{2}$ adsorption-desorption isotherm of a non-porous material. Again, in the range below $300^{\circ} \mathrm{C}$, increasing the calcination temperature produces some slight increase in the microporous surface. However, in the sample treated at $250{ }^{\circ} \mathrm{C}$, the observed increase in surface area corresponds to the non-microporous one. This effect can be related with the decrease in crystallinity and increased disorder observed by XRD. When comparing the vacuum and the air thermal treatments, no obvious differences were detected, so it seems evident that temperature is the main factor governing the purification process. Regarding the effect of the treatment time, the $\mathrm{N}_{2}$ adsorption-desorption isotherms of their corresponding samples remain typical of microporous solids (Figure 9b). Increasing the treatment time led to some moderate reduction in the BET surface area, affecting to the microporous range, while the non-microporous area was increased, probably due to the loss of crystallinity seen by XRD. Therefore, thermal treatment at moderate temperature $\left(\approx 250{ }^{\circ} \mathrm{C}\right)$ allows purifying and improving the stability of the tested MOF, while maintaining its porous structure and surface area close to $1000 \mathrm{~m}^{2} \cdot \mathrm{g}^{-1}$, analogous to other untreated $\mathrm{NH}_{2}-\mathrm{MIL}-125$ (Ti) [41-44].
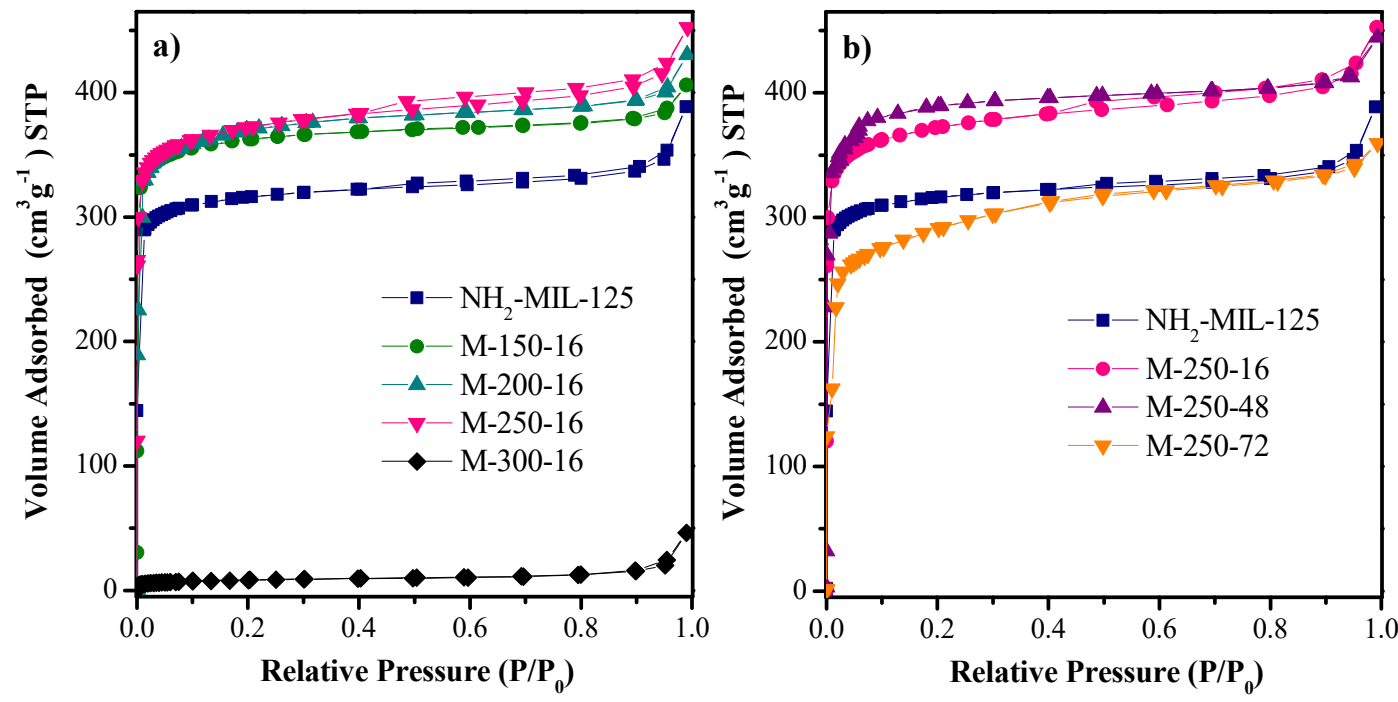

Figure 9. $\mathrm{N}_{2}$ adsorption-desorption isotherms at $-196{ }^{\circ} \mathrm{C}$ of the original $\mathrm{NH}_{2}-\mathrm{MIL}-125$ (Ti) and after heat treatment in air at different temperatures for $16 \mathrm{~h}(\mathbf{a})$ and at $250{ }^{\circ} \mathrm{C}$ for different times (b). 
Table 4. Porous texture characterization of $\mathrm{NH}_{2}-\mathrm{MIL}-125(\mathrm{Ti})$ after heat treatment in air under different conditions.

\begin{tabular}{|c|c|c|c|c|c|}
\hline Sample & $\begin{array}{c}\mathrm{S}_{\mathrm{BET}}{ }^{1} \\
\left(\mathrm{~m}^{2} \cdot \mathrm{g}^{-1}\right)\end{array}$ & $\begin{array}{c}\mathrm{S}_{\mathrm{MP}}{ }^{2} \\
\left(\mathrm{~m}^{2} \cdot \mathrm{g}^{-1}\right)\end{array}$ & $\begin{array}{c}S_{E X T}{ }^{3} \\
\left(\mathrm{~m}^{2} \cdot \mathrm{g}^{-1}\right)\end{array}$ & $\begin{array}{c}V_{T}{ }^{4} \\
\left(\mathrm{~cm}^{3} \cdot \mathrm{g}^{-1}\right)\end{array}$ & $\begin{array}{c}\mathrm{V}_{\mathrm{MP}^{5}} \\
\left(\mathrm{~cm}^{3} \cdot \mathrm{g}^{-1}\right)\end{array}$ \\
\hline Original & 1025 & 940 & 85 & 0.60 & 0.45 \\
\hline M-150-16 & 1085 & 989 & 96 & 0.63 & 0.53 \\
\hline M-200-16 & 1173 & 1075 & 98 & 0.67 & 0.54 \\
\hline M-250-16 & 1207 & 1058 & 149 & 0.70 & 0.53 \\
\hline M-300-16 & 28 & 12 & 16 & 0.07 & 0.006 \\
\hline M-250-48 & 1046 & 865 & 181 & 0.56 & 0.35 \\
\hline M-250-72 & 962 & 684 & 278 & 0.56 & 0.33 \\
\hline M-250-48-Exposed & 970 & 850 & 120 & 0.53 & 0.34 \\
\hline
\end{tabular}

${ }^{1} \mathrm{~S}_{\mathrm{BET}}$, specific surface area; ${ }^{2} \mathrm{~S}_{\mathrm{MP}}$ and ${ }^{3} \mathrm{~S}_{\mathrm{EXT}}$, microporous and non-microporous surface area; ${ }^{4} \mathrm{~V}_{\mathrm{T}}$ and ${ }^{5} \mathrm{~V}_{\mathrm{MP}}$, total and micropore volume, respectively.

Figure 10 shows the results of the stability in water of the samples subjected to calcination in air at different temperatures and times. Thermal treatment in air for $16 \mathrm{~h}$ stabilizes the $\mathrm{NH}_{2}-\mathrm{MIL}-125$ (Ti) and the leachate percentage diminishes at increasing temperature. At $250{ }^{\circ} \mathrm{C}$, this improvement of stability in water is significantly higher than the observed with the thermal vacuum treatment (see Figure 5) and now a quasi-equilibrium state is achieved. Extending the air thermal treatment up to $48 \mathrm{~h}$ reduces the leaching percentage to less than $7 \%$ and maintains the quasi-equilibrium state, although no further improvement was observed at higher treatment times. Characterization of the M-250-48 sample after water exposition for $24 \mathrm{~h}$ was carried out to check possible structural and textural changes (Figure 11). There were no significant differences in $\mathrm{X}$-ray diffractograms or $\mathrm{N}_{2}$ adsorption-desorption isotherms before and after contact with water during the above-mentioned time. The $\mathrm{S}_{\mathrm{BET}}$ slightly decreased somewhat, from 1046 to $970 \mathrm{~m}^{2} \cdot \mathrm{g}^{-1}$, but the crystallinity remained unchanged (see values in Table 3; Table 4). The $\mathrm{NH}_{2}-\mathrm{BDC}$ also remained in the structure, including the presence of the amine group, as confirmed by its UV-vis spectrum (Figure S3 in the supplementary information) that presents the characteristic absorption bands of this linker. These results demonstrate that it is possible to purify and stabilize the $\mathrm{NH}_{2}$-MIL-125(Ti) MOF by a fairly simple thermal treatment in air at $250{ }^{\circ} \mathrm{C}$ for $48 \mathrm{~h}$, without affecting its structure and porous texture.

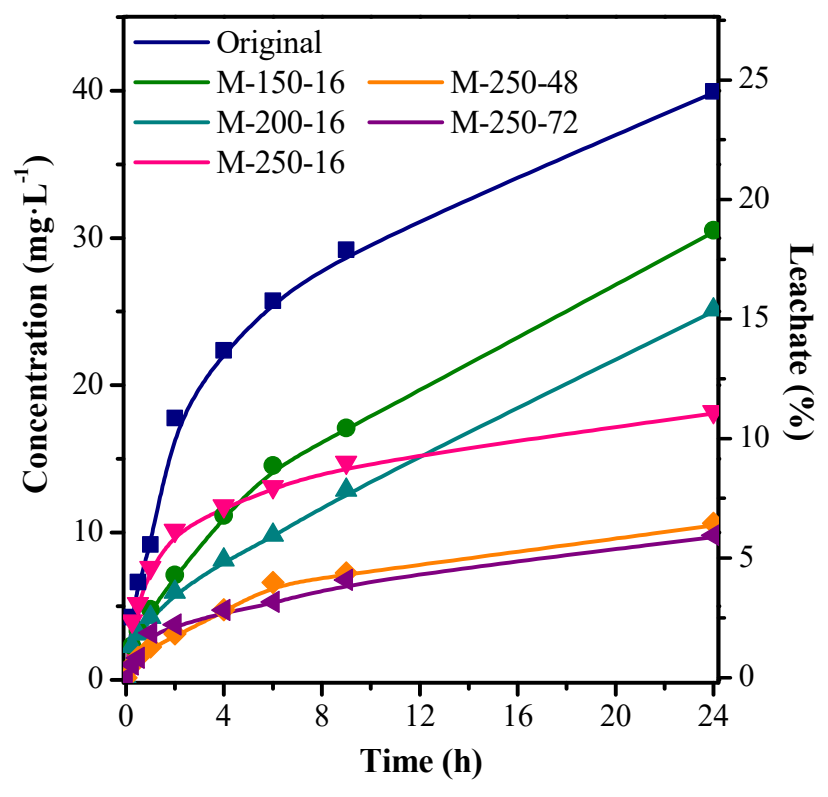

Figure 10. Linker leaching in water from the original $\mathrm{NH}_{2}-\mathrm{MIL}-125(\mathrm{Ti})$ and after heat treatment in air for $16 \mathrm{~h}$ at different temperatures and at $250{ }^{\circ} \mathrm{C}$ during different times. 

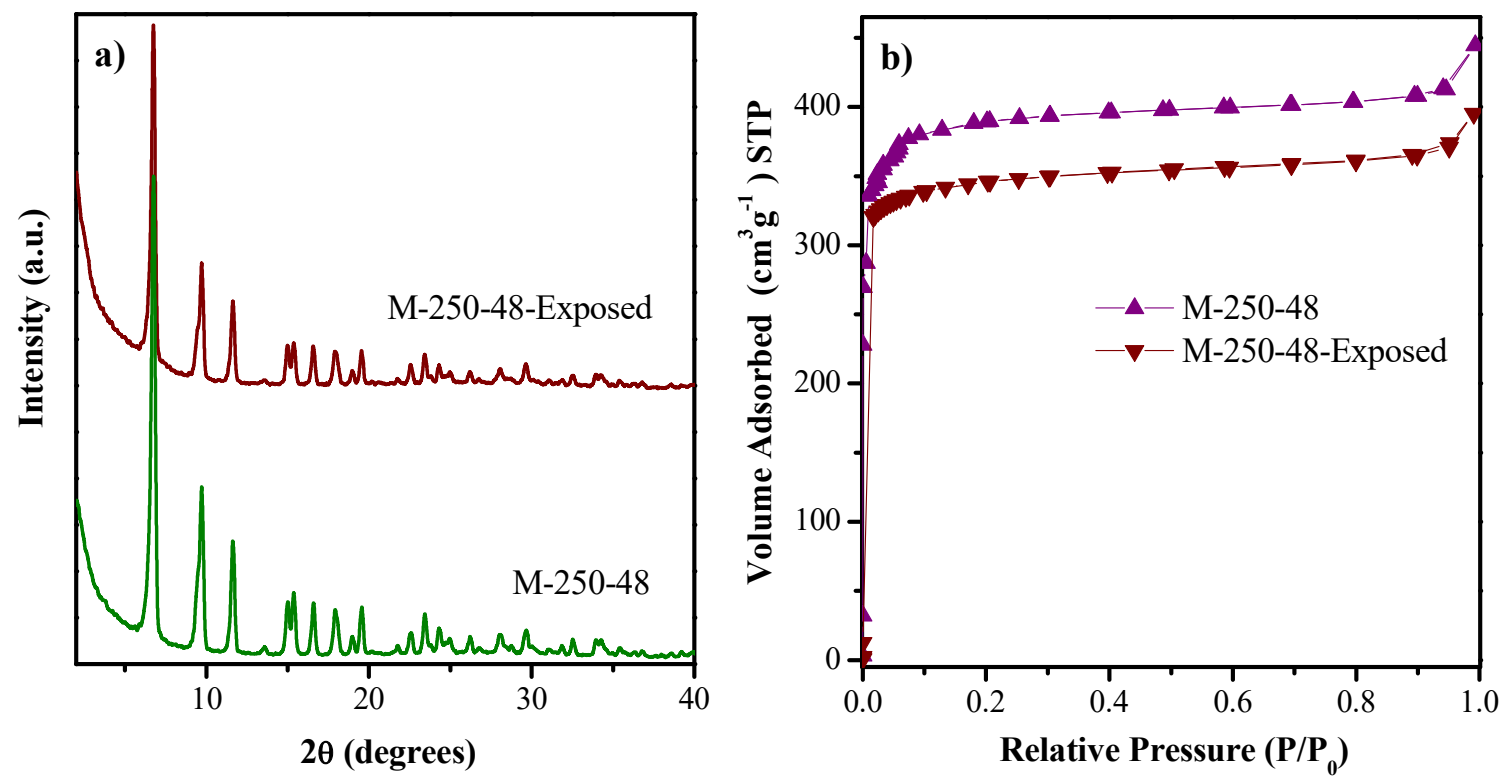

Figure 11. (a) XRD patterns and (b) $\mathrm{N}_{2}$ adsorption-desorption isotherms at $-196{ }^{\circ} \mathrm{C}$ of $\mathrm{M}-250-48$ before and after contact with water for $24 \mathrm{~h}$.

\section{Materials and Methods}

\section{1. $\mathrm{NH}_{2}-\mathrm{MIL}-125$ (Ti) Synthesis}

$\mathrm{NH}_{2}$-MIL-125(Ti) was prepared following the methodology reported in our previous work (chemical information included in Figure $\mathrm{S} 4$ in the supplementary information) [44]. Typically, 2-amino benzene dicarboxylic acid (6 mmol, $\mathrm{NH}_{2}$-BDC, Sigma Aldrich, Madrid, Spain, 99\%) was dissolved in dimethylformamide ( $25 \mathrm{~mL}$, DMF, Sigma Aldrich, Madrid, Spain, $\geq 99.8 \%$ ) under stirring. Titanium isopropoxide ( $3 \mathrm{mmol}$, Sigma Aldrich, Madrid, Spain, $\geq 98 \%$ ) was dropped onto the mixture and stirred until homogenized, after which methanol $\left(25 \mathrm{~mL}, \mathrm{CH}_{3} \mathrm{OH}\right.$, Sigma Aldrich, Madrid, Spain, anhydrous $99.8 \%$ ) was added. The whole mixture was kept in agitation for $30 \mathrm{~min}$, drawn off to a $65 \mathrm{~mL}$ Teflon autoclave and placed in an oven at $150^{\circ} \mathrm{C}$ for $16 \mathrm{~h}$. The resulting solid was recovered by centrifugation ( $5 \mathrm{~min}, 5000 \mathrm{rpm})$ and washed three times with DMF $(100 \mathrm{~mL}, 30 \mathrm{~min})$ and three times with methanol ( $100 \mathrm{~mL}, 30 \mathrm{~min})$, recovering the solid in all cases by centrifugation. The final drying of the solid was performed overnight at $60^{\circ} \mathrm{C}$.

$\mathrm{NH}_{2}$-MIL-125(Ti) was subjected to different thermal treatments. The first series was obtained by heating the $\mathrm{NH}_{2}$-MIL-125(Ti) at $150,200,250$ and $300{ }^{\circ} \mathrm{C}$ for $16 \mathrm{~h}$ under vacuum using a degassing station (Micromeritics VacPrep 061, Norcross, GA, USA) attached to the TriStar 123 equipment. For the second series, the $\mathrm{NH}_{2}$-MIL-125(Ti) was heated in a muffle furnace (Fuji Electric, MOD $12 \mathrm{PR} / 400$, Barcelona, Spain) in air at 150, 200, 250 and $300{ }^{\circ} \mathrm{C}$ for $16 \mathrm{~h}$, and also at $250{ }^{\circ} \mathrm{C}$ for 48 and $72 \mathrm{~h}$. The resulting samples were denoted as $\mathrm{X}-\mathrm{T}-\mathrm{t}$, where $\mathrm{X}$ indicated the type of treatment, $\mathrm{V}$ for vacuum and $\mathrm{M}$ for muffle furnace, $\mathrm{T}$ was the treatment temperature and $\mathrm{t}$ the treatment time.

\subsection{Characterization}

Thermogravimetric analysis was carried out using a Q600 TA instruments (New Castle, DE, USA) in an alumina crucible. All measurements were carried out within the temperature range $25-1200{ }^{\circ} \mathrm{C}$ at a heating rate of $10^{\circ} \mathrm{C} \cdot \mathrm{min}^{-1}$ under a continuous air flow of $20 \mathrm{~mL} \cdot \mathrm{min}^{-1}$. X-ray diffractograms (XRD) were registered in the $2-45^{\circ} 2 \theta$ range with a rate of $1.5^{\circ} \cdot \mathrm{min}^{-1}$ and using a $\mathrm{Cu} \mathrm{K} \alpha$ radiation. A Bruker D8 diffractometer (Bremen, Germany) was used, equipped with a Sol-X energy dispersive 
detector. Crystallinity percentage was calculated after diffractogram deconvolution with OriginPro by the following expression $[53,54]$ :

$$
\text { Crystallinity }(\%)=100 \times \frac{\text { Area of crystalline peaks }}{\text { Area of all XRD pattern }}
$$

The average crystal size was determined by using the Scherrer's equation from the reflection peak (121) of $\mathrm{NH}_{2}-\mathrm{MIL}-125$ (Ti), not overlapped with any other peak. UV-vis diffuse reflectance spectroscopy was carried out on Shimadzu UV2600i (Kyoto, Japan) equipment, recording the spectra in the 250-700 nm range. Scanning electron microscopy images (SEM) were taken with a Hitachi S4800 microscope (Krefeld, Germany) and transmission electron microscopy images (TEM) with a TECNAI G2 20 Twin equipment (Hillsborough, NC, USA). $\mathrm{N}_{2}$ adsorption-desorption isotherms at $-196{ }^{\circ} \mathrm{C}$ were carried out with a TriStar 123 equipment (Micromeritics II 3020, Norcross, GA, USA). Solids were outgassed before testing under vacuum at $120^{\circ} \mathrm{C}$ for $18 \mathrm{~h}$. Specific surface area $\left(\mathrm{S}_{\mathrm{BET}}\right)$ was calculated by the Brunauer-Emmet-Teller method [55], while micropore surface area $\left(\mathrm{S}_{\mathrm{MP}}\right)$ was obtained using the $t$-plot method [56] and the external or non-microporous surface area $\left(\mathrm{S}_{\mathrm{EXT}}\right)$ by difference between $\mathrm{S}_{\mathrm{BET}}$ and $\mathrm{S}_{\mathrm{MP}}$. The total pore volume $\left(\mathrm{V}_{\mathrm{T}}\right)$ corresponded to the amount of nitrogen adsorbed at a relative pressure of 0.99 , while the micropore volume $\left(\mathrm{V}_{\mathrm{MP}}\right)$ was obtained from the $t$-plot method.

\subsection{Stability Testing in Water}

The water stability of the $\mathrm{NH}_{2}$-MIL-125(Ti) derived solids was tested through the leaching of the $\mathrm{NH}_{2}-\mathrm{BDC}$ in deionized water (Type II). The solid was suspended in water $\left(250 \mathrm{mg} \cdot \mathrm{L}^{-1}\right)$ and stirred for $24 \mathrm{~h}$ at $25^{\circ} \mathrm{C}$ and $170 \mathrm{rpm}$ in a water bath orbital shaker (JULABO SW22, Seelbach, Germany). At different interval times, aliquots of $2 \mathrm{~mL}$ were collected and filtered with Polytetrafluoroethylene (PTFE) syringe filters (Whatman $0.45 \mu \mathrm{m}$ ). The filtrates were analyzed to determine the concentration of the ligand by high performance liquid chromatography (HPLC) (Shimadzu Prominence-I LC-2030C, Kyoto, Japan), equipped with a diode array detector (SPDM30 A) and a C18 column (Eclipse Plus, $5 \mu \mathrm{m}$ ). A gradient elution method was used for the analyses, changing the mobile phase (aqueous acetic acid solution $0.1 \%$, Sigma Aldrich, Madrid, Spain, $\geq 99 \%$ ) by elution with acetonitrile (HPLC grade, Scharlab, Barcelona, Spain) and using a constant flow of $0.7 \mathrm{~mL} \cdot \mathrm{min}^{-1}$. The wavelength of the detector was fixed at $358 \mathrm{~nm}$ for the detection of the $\mathrm{NH}_{2}$-BDC that appeared at a 6.3 min retention time. Solid samples were recovered from the aqueous medium by centrifugation after stability test and stored for later characterization.

\section{Conclusions}

Water stability of $\mathrm{NH}_{2}$-MIL-125(Ti) was studied by analyzing quantitatively the amount of ligand released to the liquid phase along the exposition time in water. In many studies, the water stability of MOFs has been mainly investigated using the $\mathrm{X}$-ray diffraction, $\mathrm{N}_{2}$ adsorption-desorption and electron microscopy of filtered powders, comparing the properties before and after exposition. This study shows that these characterization techniques are not enough to assess that stability. We demonstrated, for the first time, the quantitative lixiviation of this MOF, which achieved values up to $25 \%$ after $24 \mathrm{~h}$ of contact, with water still being far from equilibrium after that time. The present study also shows that the post-modification of $\mathrm{NH}_{2}$-MIL-125(Ti) by thermal treatments stabilizes its structure, making it less susceptible to partial dissolution. Temperature and time showed to be the determining variables, while the atmosphere (air or vacuum) showed no significant effect. Thermal treatment under these two atmospheres within $150-250{ }^{\circ} \mathrm{C}$ did not alter the structure and porous texture of the MOF, except for some slight increase in the specific surface area accompanied by a small reduction in crystallinity. Increasing the treatment temperature up to $300{ }^{\circ} \mathrm{C}$ caused the collapse of the crystalline MOF structure accompanied by the loss of the pore network. Certain reduction on the surface area were observed by extending the thermal treatment but maintaining its structure. 
The results obtained provide a new understanding of the effects of thermal treatments on the water stability of $\mathrm{NH}_{2}$-MIL-125(Ti), which was improved as the temperature of the treatment increased up to $250{ }^{\circ} \mathrm{C}$. Some significant differences were found on the effects of the atmosphere used in the thermal treatment. Under air, greater stabilization of the MOF was achieved due to the removal of excess linker molecules, with lower leaching percentages and the attainment of a quasi-equilibrium state in a relatively low contact time in water. The best results were obtained upon thermal treatment in air at $250{ }^{\circ} \mathrm{C}$ for $48 \mathrm{~h}$. After that treatment, less than $7 \%$ ligand leaching occurred upon $24 \mathrm{~h}$ of contact with water. These findings have significant implications regarding the potential use of MOFs in water-related applications.

Supplementary Materials: The following are available online at http://www.mdpi.com/2073-4344/10/6/603/s1, Figure S1: UV-vis diffuse absorbance spectra of $\mathrm{NH}_{2}-\mathrm{MIL}-125$ (Ti) treated under vacuum at different temperatures for $16 \mathrm{~h}$. Original $\mathrm{NH}_{2}-\mathrm{MIL}-125$ (Ti) and MIL-125(Ti) spectra are included as reference, Figure S2: UV-vis diffuse absorbance spectra of $\mathrm{NH}_{2}$-MIL-125(Ti) heated in air at different temperatures for $16 \mathrm{~h}(\mathbf{a})$ and at $250{ }^{\circ} \mathrm{C}$ for 48 and $72 \mathrm{~h} \mathrm{(b).} \mathrm{Original} \mathrm{NH}_{2}$-MIL-125(Ti) and MIL-125(Ti) spectra are included as reference, Figure S3: UV-vis diffuse absorbance spectra of M-250-48 before and after contact with water for $24 \mathrm{~h}$. Original NH $\mathrm{N}_{2}-\mathrm{MIL}^{-125(T i)}$ and MIL-125(Ti) spectra are included as reference, Figure S4: (a) Chemical structure of Ti-oxo clusters linked to $\mathrm{NH}_{2}$-BDC ligands, from the Cambridge Structural Database (CSD). Chemical structure of $\mathrm{NH}_{2}-\mathrm{MIL}-125$ (Ti) viewed from a-axis (b) and c-axis (c), from cif data of Crystallography Open Database.

Author Contributions: Conceptualization, J.B., C.B. and J.J.R.; methodology, A.G.-A. and V.M.-R.; writingoriginal draft preparation, A.G.-A. and C.B.; writing—review and editing, A.G.-A., V.M.-R., J.B., C.B. and J.J.R.; supervision, J.B., C.B., J.J.R.; funding acquisition, J.B., C.B. and J.J.R. All authors have read and agree to the published version of the manuscript.

Funding: This research was funded by Spanish MINECO (project CTQ2016-78576-R).

Acknowledgments: V. Muelas-Ramos thanks to Spanish MCIU for BES-2017-082613 grant.

Conflicts of Interest: The authors declare no conflict of interest.

\section{References}

1. Qiu, J.; Zhang, X.; Feng, Y.; Zhang, X.; Wang, H.; Yao, J. Modified metal-organic frameworks as photocatalysts. Appl. Catal. B Environ. 2018, 231,317-342. [CrossRef]

2. Furukawa, H.; Cordova, K.E.; O'Keeffe, M.; Yaghi, O.M. The chemistry and applications of metal-organic frameworks. Science 2013, 341, 1230444. [CrossRef] [PubMed]

3. Szczęśniak, B.; Choma, J.; Jaroniec, M. Gas adsorption properties of hybrid graphene-MOF materials. J. Colloid Interface Sci. 2018, 514, 801-813. [CrossRef]

4. Millward, A.R.; Yaghi, O.M. Metal-organic frameworks with exceptionally high capacity for storage of carbon dioxide at room temperature. J. Am. Chem. Soc. 2005, 127, 17998-17999. [CrossRef] [PubMed]

5. Rasheed, T.; Nabeel, F. Luminescent metal-organic frameworks as potential sensory materials for various environmental toxic agents. Coord. Chem. Rev. 2019, 401, 213065. [CrossRef]

6. Kreno, L.E.; Leong, K.; Farha, O.K.; Allendorf, M.; Van Duyne, R.P.; Hupp, J.T. Metal-organic framework materials as chemical sensors. Chem. Rev. 2012, 112, 1105-1125. [CrossRef] [PubMed]

7. Qiu, S.; Xue, M.; Zhu, G. Metal-organic framework membranes: From synthesis to separation application. Chem. Soc. Rev. 2014, 43, 6116-6140. [CrossRef]

8. Abánades Lázaro, I.; Forgan, R.S. Application of zirconium MOFs in drug delivery and biomedicine. Coord. Chem. Rev. 2019, 380, 230-259. [CrossRef]

9. Sun, C.-Y.; Qin, C.; Wang, X.-L.; Su, Z.-M. Metal-organic frameworks as potential drug delivery systems. Expert Opin. Drug Deliv. 2013, 10, 89-101. [CrossRef]

10. Joseph, L.; Jun, B.-M.; Jang, M.; Park, C.M.; Muñoz-Senmache, J.C.; Hernández-Maldonado, A.J.; Heyden, A.; Yu, M.; Yoon, Y. Removal of contaminants of emerging concern by metal-organic framework nanoadsorbents: A review. Chem. Eng. J. 2019, 369, 928-946. [CrossRef]

11. Li, X.; Wang, B.; Cao, Y.; Zhao, S.; Wang, H.; Feng, X.; Zhou, J.; Ma, X. Water contaminant elimination based on metal-organic frameworks and perspective on their industrial applications. ACS Sustain. Chem. Eng. 2019, 7, 4548-4563. [CrossRef] 
12. Hasan, Z.; Jhung, S.H. Removal of hazardous organics from water using metal-organic frameworks (MOFs): Plausible mechanisms for selective adsorptions. J. Hazard. Mater. 2015, 283, 329-339. [CrossRef] [PubMed]

13. Bedia, J.; Muelas-Ramos, V.; Peñas-Garzón, M.; Gómez-Avilés, A.; Rodríguez, J.J.; Belver, C. A review on the synthesis and characterization of metal organic frameworks for photocatalytic water purification. Catalysts 2019, 9, 52. [CrossRef]

14. Khan, N.A.; Hasan, Z.; Jhung, S.H. Adsorptive removal of hazardous materials using metal-organic frameworks (MOFs): A review. J. Hazard. Mater. 2013, 244-245, 444-456. [CrossRef] [PubMed]

15. Pi, Y.; Li, X.; Xia, Q.; Wu, J.; Li, Y.; Xiao, J.; Li, Z. Adsorptive and photocatalytic removal of Persistent Organic Pollutants (POPs) in water by metal-organic frameworks (MOFs). Chem. Eng. J. 2018, 337, 351-371. [CrossRef]

16. Feng, M.; Zhang, P.; Zhou, H.C.; Sharma, V.K. Water-stable metal-organic frameworks for aqueous removal of heavy metals and radionuclides: A review. Chemosphere 2018, 209, 783-800. [CrossRef]

17. Sharma, V.K.; Feng, M. Water depollution using metal-organic frameworks-catalyzed advanced oxidation processes: A review. J. Hazard. Mater. 2019, 372, 3-16. [CrossRef]

18. Li, Y.; Xu, H.; Ouyang, S.; Ye, J. Metal-organic frameworks for photocatalysis. Phys. Chem. Chem. Phys. 2016, 18, 7563-7572. [CrossRef]

19. Zeng, L.; Guo, X.; He, C.; Duan, C. Metal-organic frameworks: Versatile materials for heterogeneous photocatalysis. ACS Catal. 2016, 6, 7935-7947. [CrossRef]

20. Li, W.; Zhang, Y.; Li, Q.; Zhang, G. Metal-organic framework composite membranes: Synthesis and separation applications. Chem. Eng. Sci. 2015, 135, 232-257. [CrossRef]

21. Canivet, J.; Fateeva, A.; Guo, Y.; Coasne, B.; Farrusseng, D. Water adsorption in MOFs: Fundamentals and applications. Chem. Soc. Rev. 2014, 43, 5594-5617. [CrossRef] [PubMed]

22. Furukawa, H.; Gándara, F.; Zhang, Y.-B.; Jiang, J.; Queen, W.L.; Hudson, M.R.; Yaghi, O.M. Water adsorption in porous metal-organic frameworks and related materials. J. Am. Chem. Soc. 2014, 136, 4369-4381. [CrossRef]

23. De Toni, M.; Jonchiere, R.; Pullumbi, P.; Coudert, F.X.; Fuchs, A.H. How can a hydrophobic mof be water-unstable? Insight into the hydration mechanism of IRMOFs. Chem. Phys. Chem 2012, 13, 3497-3503. [CrossRef] [PubMed]

24. Qian, X.; Yadian, B.; Wu, R.; Long, Y.; Zhou, K.; Zhu, B.; Huang, Y. Structure stability of metal-organic framework MIL-53 (Al) in aqueous solutions. Int. J. Hydrogen Energy 2013, 38, 16710-16715. [CrossRef]

25. Low, J.J.; Benin, A.I.; Jakubczak, P.; Abrahamian, J.F.; Faheem, S.A.; Willis, R.R. Virtual high throughput screening confirmed experimentally: Porous coordination polymer hydration. J. Am. Chem. Soc. 2009, 131, 15834-15842. [CrossRef]

26. Bon, V.; Senkovska, I.; Baburin, I.A.; Kaskel, S. Zr- and Hf-based metal-organic frameworks: Tracking down the polymorphism. Cryst. Growth Des. 2013, 13, 1231-1237. [CrossRef]

27. Jeremias, F.; Lozan, V.; Henninger, S.K.; Janiak, C. Programming MOFs for water sorption: Aminofunctionalized MIL-125 and UiO-66 for heat transformation and heat storage applications. Dalt. Trans. 2013, 42, 15967-15973. [CrossRef]

28. Bai, Y.; Dou, Y.; Xie, L.-H.; Rutledge, W.; Li, J.-R.; Zhou, H.-C. Zr-based metal-organic frameworks: Design, synthesis, structure, and applications. Chem. Soc. Rev. 2016, 45, 2327-2367. [CrossRef]

29. Burtch, N.C.; Jasuja, H.; Walton, K.S. Water stability and adsorption in metal-organic frameworks. Chem. Rev. 2014, 114, 10575-10612. [CrossRef]

30. Zhu, J.; Li, P.Z.; Guo, W.; Zhao, Y.; Zou, R. Titanium-based metal-organic frameworks for photocatalytic applications. Coord. Chem. Rev. 2018, 359, 80-101. [CrossRef]

31. Zou, D.-H.; Cui, L.-N.; Liu, P.-Y.; Yang, S.; Zhu, Q.-Y.; Dai, J. Triphenylamine derived titanium oxo clusters: An approach to effective organic-inorganic hybrid dyes for photoactive electrodes. Chem. Commun. 2018, 54, 9933-9936. [CrossRef] [PubMed]

32. Kim, S.; Sarkar, D.; Kim, Y.; Park, M.H.; Yoon, M.; Kim, Y.; Kim, M. Synthesis of functionalized titanium-carboxylate molecular clusters and their catalytic activity. J. Ind. Eng. Chem. 2017, 53, 171-176. [CrossRef]

33. Zuluaga, S.; Fuentes-Fernandez, E.M.A.; Tan, K.; Xu, F.; Li, J.; Chabal, Y.J.; Thonhauser, T. Understanding and controlling water stability of MOF-74. J. Mater. Chem. A 2016, 4, 5176-5183. [CrossRef] 
34. Canivet, J.; Bonnefoy, J.; Daniel, C.; Legrand, A.; Coasne, B.; Farrusseng, D. Structure-property relationships of water adsorption in metal-organic frameworks. New J. Chem. 2014, 38, 3102-3111. [CrossRef]

35. Howarth, A.J.; Peters, A.W.; Vermeulen, N.A.; Wang, T.C.; Hupp, J.T.; Farha, O.K. Best practices for the synthesis, activation, and characterization of metal-organic frameworks. Chem. Mater. 2017, 29, $26-39$. [CrossRef]

36. Taheri, M.; Enge, T.G.; Tsuzuki, T. Water stability of cobalt doped ZIF-8: A quantitative study using optical analyses. Mater. Today Chem. 2020, 16, 100231. [CrossRef]

37. Wen, G.; Guo, Z. Facile modification of $\mathrm{NH}_{2}-\mathrm{MIL}-125$ (Ti) to enhance water stability for efficient adsorptive removal of crystal violet from aqueous solution. Colloids Surfaces A Physicochem. Eng. Asp. 2018, 541, $58-67$. [CrossRef]

38. Li, S.; Feng, F.; Chen, S.; Zhang, X.; Liang, Y.; Shan, S. Preparation of UiO-66- $\mathrm{NH}_{2}$ and UiO-66-NH $2 /$ sponge for adsorption of 2,4-dichlorophenoxyacetic acid in water. Ecotoxicol. Environ. Saf. 2020, 194, 110440. [CrossRef]

39. Zhang, M.; Yang, K.; Cui, J.; Yu, H.; Wang, Y.; Shan, W.; Lou, Z.; Xiong, Y. 3D-agaric like core-shell architecture UiO-66-NH $\mathrm{N}_{2} @ Z \mathrm{ZIF}-8$ with robust stability for highly efficient REEs recovery. Chem. Eng. J. 2020, 386, 124023. [CrossRef]

40. Fang, S.-Y.; Zhang, P.; Gong, J.-L.; Tang, L.; Zeng, G.-M.; Song, B.; Cao, W.-C.; Li, J.; Ye, J. Construction of highly water-stable metal-organic framework UiO-66 thin-film composite membrane for dyes and antibiotics separation. Chem. Eng. J. 2020, 385, 123400. [CrossRef]

41. Sun, D.; Ye, L.; Li, Z. Visible-light-assisted aerobic photocatalytic oxidation of amines to imines over $\mathrm{NH}_{2}$-MIL-125(Ti). Appl. Catal. B Environ. 2015. [CrossRef]

42. Wang, H.; Yuan, X.; Wu, Y.; Zeng, G.; Dong, H.; Chen, X.; Leng, L.; Wu, Z.; Peng, L. In situ synthesis of $\mathrm{In}_{2} \mathrm{~S}_{3} @ \mathrm{MIL}-125$ (Ti) core-shell microparticle for the removal of tetracycline from wastewater by integrated adsorption and visible-light-driven photocatalysis. Appl. Catal. B Environ. 2016, 186, 19-29. [CrossRef]

43. Zhu, S.-R.; Liu, P.-F.; Wu, M.-K.; Zhao, W.-N.; Li, G.-C.; Tao, K.; Yi, F.-Y.; Han, L. Enhanced photocatalytic performance of $\mathrm{BiOBr} / \mathrm{NH}_{2}-\mathrm{MIL}-125$ (Ti) composite for dye degradation under visible light. Dalt. Trans. 2016, 45, 17521-17529. [CrossRef] [PubMed]

44. Gómez-Avilés, A.; Peñas-Garzón, M.; Bedia, J.; Dionysiou, D.D.; Rodríguez, J.J.; Belver, C. Mixed Ti-Zr metal-organic-frameworks for the photodegradation of acetaminophen under solar irradiation. Appl. Catal. B Environ. 2019, 253, 253-262. [CrossRef]

45. Fu, Y.; Sun, D.; Chen, Y.; Huang, R.; Ding, Z.; Fu, X.; Li, Z. An amine-functionalized titanium metal-organic framework photocatalyst with visible-light-induced activity for $\mathrm{CO}_{2}$ reduction. Angew. Chemie Int. Ed. 2012, 51, 3364-3367. [CrossRef] [PubMed]

46. Dan-Hardi, M.; Serre, C.; Frot, T.; Rozes, L.; Maurin, G.; Sanchez, C.; Férey, G. A new photoactive crystalline highly porous titanium (IV) dicarboxylate. J. Am. Chem. Soc. 2009, 131, 10857-10859. [CrossRef]

47. Zhang, Y.; Chen, Y.; Zhang, Y.; Cong, H.; Fu, B.; Wen, S.; Ruan, S. A novel humidity sensor based on $\mathrm{NH}_{2}$-MIL-125(Ti) metal organic framework with high responsiveness. J. Nanoparticle Res. 2013, 15, 2014. [CrossRef]

48. Wang, H.; Yuan, X.; Wu, Y.; Zeng, G.; Chen, X.; Leng, L.; Wu, Z.; Jiang, L.; Li, H. Facile synthesis of amino-functionalized titanium metal-organic frameworks and their superior visible-light photocatalytic activity for Cr(VI) reduction. J. Hazard. Mater. 2015, 286, 187-194. [CrossRef]

49. Kim, S.-N.; Kim, J.; Kim, H.-Y.; Cho, H.-Y.; Ahn, W.-S. Adsorption/catalytic properties of MIL-125 and $\mathrm{NH}_{2}$-MIL-125. Catal. Today 2013, 204, 85-93. [CrossRef]

50. Wang, F.; Li, F.-L.; Xu, M.-M.; Yu, H.; Zhang, J.-G.; Xia, H.-T.; Lang, J.-P. Facile synthesis of a Ag(i)-doped coordination polymer with enhanced catalytic performance in the photodegradation of azo dyes in water. J. Mater. Chem. A 2015, 3, 5908-5916. [CrossRef]

51. Fan, Y.-H.; Zhang, S.-W.; Qin, S.-B.; Li, X.-S.; Qi, S.-H. An enhanced adsorption of organic dyes onto $\mathrm{NH}_{2}$ functionalization titanium-based metal-organic frameworks and the mechanism investigation. Microporous Mesoporous Mater. 2018, 263, 120-127. [CrossRef]

52. Wu, Z.; Huang, X.; Zheng, H.; Wang, P.; Hai, G.; Dong, W.; Wang, G. Aromatic heterocycle-grafted $\mathrm{NH}_{2}$-MIL-125(Ti) via conjugated linker with enhanced photocatalytic activity for selective oxidation of alcohols under visible light. Appl. Catal. B Environ. 2018, 224, 479-487. [CrossRef]

53. Klug, H.P.; Alexander, L.E. X-Ray Diffraction Procedures: For Polycrystalline and Amorphous Materials, 2nd ed.; Wiley: Hoboken, NJ, USA, 1974; ISBN 978-0-471-49369-3. 
54. Arbain, R.; Othman, M.; Palaniandy, S. Preparation of iron oxide nanoparticles by mechanical milling. Miner. Eng. 2011, 24, 1-9. [CrossRef]

55. Brunauer, S.; Emmett, P.H.; Teller, E. Adsorption of gases in multimolecular layers. J. Am. Chem. Soc. 1938, 60, 309-319. [CrossRef]

56. Lippens, B.C.; De Boer, J.H. Studies on pore systems in catalysts V. The t method. J. Catal. 1965, 4, 319-323. [CrossRef]

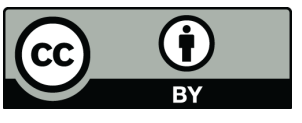

(C) 2020 by the authors. Licensee MDPI, Basel, Switzerland. This article is an open access article distributed under the terms and conditions of the Creative Commons Attribution (CC BY) license (http://creativecommons.org/licenses/by/4.0/). 